\title{
Methods of Sentinel Lymph Node Detection and Management in Urinary Bladder Cancer-A Narrative Review
}

\author{
Ankit Sinha ${ }^{1, *(\mathbb{C}}$, Alexander West ${ }^{1}$, John Hayes ${ }^{1}$, Jeremy Teoh ${ }^{2} \mathbb{C}$, Karel Decaestecker ${ }^{3}$ and Nikhil Vasdev ${ }^{1,4} \mathbb{C}^{(0)}$ \\ 1 Hertfordshire and Bedfordshire Urological Cancer Centre, Lister Hospital, Stevenage SG1 4AB, UK; \\ alexander.west2@nhs.net (A.W.); john.hayes13@nhs.net (J.H.); nikhil.vasdev@nhs.net (N.V.) \\ 2 S.H. Ho Urology Centre, Department of Surgery, The Chinese University of Hong Kong, Hong Kong, China; \\ jeremyteoh@surgery.cuhk.edu.hk \\ 3 Department of Urology, University of Ghent Hospital, 9000 Ghent, Belgium; karel.decaestecker@ugent.be \\ 4 School of Life and Medical Sciences, University of Hertfordshire, Hertfordshire AL10 9AB, UK \\ * Correspondence: ankit.sinha1@nhs.net
}

check for updates

Citation: Sinha, A.; West, A.; Hayes, J.; Teoh, J.; Decaestecker, K.; Vasdev,

N. Methods of Sentinel Lymph Node Detection and Management in

Urinary Bladder Cancer-A

Narrative Review. Curr. Oncol. 2022, 29, 1335-1348. https://doi.org/ 10.3390 /curroncol29030114

Received: 5 January 2022

Accepted: 21 February 2022

Published: 23 February 2022

Publisher's Note: MDPI stays neutral with regard to jurisdictional claims in published maps and institutional affiliations.

Copyright: (c) 2022 by the authors. Licensee MDPI, Basel, Switzerland. This article is an open access article distributed under the terms and conditions of the Creative Commons Attribution (CC BY) license (https:// creativecommons.org/licenses/by/ $4.0 /)$.

\begin{abstract}
Introduction: Detection of lymph node status in bladder cancer significantly impacts clinical decisions regarding its management. There is a wide range of detection modalities for this task, including lymphoscintigraphy, computed tomography, magnetic resonance imaging, single-photon emission computed tomography, positron emission tomography, and fluoroscopy. We aimed to study the pre- and intraoperative detection modalities of sentinel lymph nodes in urinary bladder cancer. Method: This narrative review was performed by searching the PubMed and EMBASE libraries using the following search terms: ("Transitional cell carcinoma of the bladder" OR "urothelial cancer" OR "urinary bladder cancer" OR "bladder cancer") AND (("sentinel lymph node”) OR ("lymphatic mapping") OR ("lymphoscintigraphy") OR ("lymphangiography") OR ("lymph node metastases")). Studies analysing the effectiveness and outcomes of sentinel lymph node detection in bladder cancer were included, while non-English language, duplicates, and non-article studies were excluded. After analysing the libraries and a further manual search of bibliographies, 31 studies were included in this paper. We followed the RAMESES publication standard for narrative reviews to produce this paper. Results: Of the 31 studies included, 7 studies included multiple detection methods; 5 studies included lymphoscintigraphy; 5 studies included computed tomography and/or singlephoton emission computed tomography; 5 studies included fluoroscopy; 4 studies included magnetic resonance imaging; and 5 studies included positron emission tomography. Discussion: Anatomical, radioactive, and functional detection modalities have been studied independently and in combination. The consensus is that preoperative detection with imaging helps guide surgical management and intraoperative detection methods help capture any lymph nodes that may have been missed. Each of these types of detection represent their own set of benefits and drawbacks, but there is currently limited evidence to support any change in overall practice to replace conventional staging.
\end{abstract}

Keywords: bladder cancer; sentinel lymph nodes; detection; imaging; PLND

\section{Introduction}

Bladder cancer is the fourth most common cancer in men and the tenth most common in women. It has the highest lifetime cost per patient of all cancer types due to the longterm survival rate and intensive surveillance that is used [1]. Locally advanced disease is optimally managed with radical cystectomy and urinary diversion, which is associated with the worst health-related quality of life among all cancer patients $[2,3]$.

Muscle invasive bladder cancer (MIBC) has a mortality rate of $50 \%$ over 5 years despite optimal management and no histopathologic signs of lymph node metastases [4,5]. This suggests half of patients have disease dissemination that is not detected by current staging techniques [6,7]. As lymph node metastases are associated with negative prognosis, radical cystectomy is routinely combined with lymphadenectomy as routine management 
of MIBC [5,6,8,9]. The extent of lymph node dissection is a highly debated topic, as it represents a fine balance between minimising disease spread with longer surgeries and complications, such as bleeding and lymphocoele development [8].

Although lymph node biopsy is pertinent in bladder cancer, the current templates of limited, standard, extended, and super extended pelvic lymph node dissection (PLND) could be improved through the use of lymph node mapping. This can aid selective resection of invaded LNs similar to the techniques used in breast and melanoma tumours [8]. An important aspect of LN mapping is detection of sentinel lymph nodes (SLNs) to assess nodal disease status. SLNs are thought to be the first draining lymph nodes from the cancer site and therefore reflect the pathologic status of the remaining lymphatic region. SLN biopsy has been shown to be a useful step in evaluating disease spread in melanoma, penile, and breast cancer $[9,10]$.

Currently, there is an unmet need for more sensitive and anatomically accurate detection of bladder cancer and SLNs. Improved disease localisation through the detection of positive lymph nodes may allow early detection and prevention of disease progression. This paper looks to assess the current literature and practice in SLN identification and biopsy in bladder cancer, as well as identifying potential novel methods.

\section{Materials and Methods}

This narrative review highlights the areas where research exists and where ongoing research can be directed. The aim is to succinctly summarise the field regarding sentinel lymph node identification and biopsy in bladder cancer as well as highlight new and novel research and technology. The RAMESES publication standard for narrative reviews was followed to produce this paper [11].

PUBMED and EMBASE databases were searched by two independent authors. The search terms used were: "Transitional cell carcinoma of the bladder", "urothelial cancer", "urinary bladder cancer", "bladder cancer", "sentinel lymph node", "lymphatic mapping", "lymphoscintigraphy", "lymphangiography", and "lymph node metastases". No language or date filtering criteria were applied to the initial search, and 53 studies were returned. Manual search of relevant article bibliographies increased this total to 71 studies. The title and abstract were read by authors independently to screen for relevance. Articles that were not agreed upon were then discussed with a third author regarding its inclusion. Exclusion criteria included non-English language, books, theses, comments, conference papers, any duplicates, and papers deemed not relevant after author review. These are summarised in Table 1. As per Figure 1, 31 studies were included in the review after the screening process, summarised in Table 2.

Table 1. Table showing the inclusion and exclusion criteria for data collection.

\begin{tabular}{cc}
\hline Inclusion & Exclusion \\
\hline $\begin{array}{c}\text { Articles analysing the effectiveness and } \\
\text { outcomes of SLN mapping in bladder cancer }\end{array}$ & Studies that were not in English language \\
Any date published & Duplicated articles \\
Animal and human studies & Books, theses, conference articles, comments \\
Irrelevant content
\end{tabular}

Table 2. This table summarises the studies included in this review.

\begin{tabular}{lcccccc}
\hline No. & Author & Year & Study Type & Reference & Imaging Modalities & Number of Patients \\
\hline 1 & Zarifmahmoudi et al. & 2019 & $\begin{array}{c}\text { Systematic Review and } \\
\text { Meta-Analysis }\end{array}$ & {$[12]$} & $\begin{array}{c}\text { Lymphoscintigraphy, CT, } \\
\text { SPECT, Fluoroscopy }\end{array}$ & 336 \\
2 & Polom et al. & 2017 & Prospective & {$[13]$} & Lymphoscintigraphy, & 50 \\
3 & Lusuardi et al. & 2013 & Review & {$[14]$} & Cluoroscopy & 522 \\
4 & Salminen et al. & 2016 & Review & {$[15]$} & CT, MRI, PET & 370 \\
\hline
\end{tabular}


Table 2. Cont.

\begin{tabular}{|c|c|c|c|c|c|c|}
\hline No. & Author & Year & Study Type & Reference & Imaging Modalities & Number of Patients \\
\hline 5 & Liss et al. & 2015 & $\begin{array}{l}\text { Systematic Review and } \\
\text { Meta-Analysis }\end{array}$ & {$[8]$} & $\begin{array}{l}\text { Lymphoscintigraphy, CT, } \\
\text { SPECT, Fluoroscopy }\end{array}$ & 156 \\
\hline 6 & Nissenkorn et al. & 1986 & Prospective & [16] & Lymphoscintigraphy, CT & 26 \\
\hline 7 & Aljabery et al. & 2015 & Retrospective & [17] & PET, CT & 54 \\
\hline 8 & Liedberg et al. & 2006 & Prospective & [18] & Lymphoscintigraphy & 75 \\
\hline 9 & Marits et al. & 2006 & Prospective & [19] & Lymphoscintigraphy & 14 \\
\hline 10 & Zarifmahmoudi et al. & 2020 & Prospective & [20] & Lymphoscintigraphy & 41 \\
\hline 11 & Aljabery et al. & 2017 & Prospective & [6] & Lymphoscintigraphy & 103 \\
\hline 12 & Sherif et al. & 2001 & Prospective & [21] & Lymphoscintigraphy & 13 \\
\hline 13 & Połom et al. & 2016 & Prospective & [22] & $\mathrm{CT}$ & 38 \\
\hline 14 & Sherif et al. & 2006 & Prospective & [4] & CT, SPECT & 6 \\
\hline 15 & Salo et al. & 1986 & Prospective & [23] & $\mathrm{CT}$ & 51 \\
\hline 16 & Lerman et al. & 2006 & Prospective & [24] & CT, SPECT & 157 \\
\hline 17 & Paik et al. & 2000 & Retrospective & [25] & $\mathrm{CT}$ & 82 \\
\hline 18 & Patel et al. & 2016 & Review & [26] & Fluoroscopy & $\mathrm{N} / \mathrm{A}$ \\
\hline 19 & Aoun et al. & 2018 & $\begin{array}{l}\text { Systematic Review and } \\
\text { Meta-Analysis }\end{array}$ & [27] & Fluoroscopy & 271 \\
\hline 20 & Schaafsma et al. & 2014 & Prospective & [28] & Fluoroscopy & 21 \\
\hline 21 & Manny et al. & 2014 & Prospective & [29] & Fluoroscopy & 10 \\
\hline 22 & Knapp et al. & 2007 & Prospective & [30] & Fluoroscopy & $\mathrm{N} / \mathrm{A}$ \\
\hline 23 & Papalia et al. & 2012 & Prospective & [31] & MRI & 36 \\
\hline 24 & Thoeny et al. & 2009 & Prospective & [32] & MRI & 21 \\
\hline 25 & Triantafyllou et al. & 2013 & Prospective & [33] & MRI & 75 \\
\hline 26 & Birkhäuser et al. & 2013 & Prospective & [34] & MRI & 75 \\
\hline 27 & Dason et al. & 2020 & Retrospective & [35] & CT, PET & 185 \\
\hline 28 & Abrahamsson et al. & 2017 & Prospective & [36] & PET & 88 \\
\hline 29 & Powles et al. & 2007 & Review & [37] & CT, PET & $\mathrm{N} / \mathrm{A}$ \\
\hline 30 & Schöder et al. & 2004 & Review & [38] & PET & $\mathrm{N} / \mathrm{A}$ \\
\hline 31 & Nayak et al. & 2013 & Prospective & [39] & PET & 25 \\
\hline
\end{tabular}

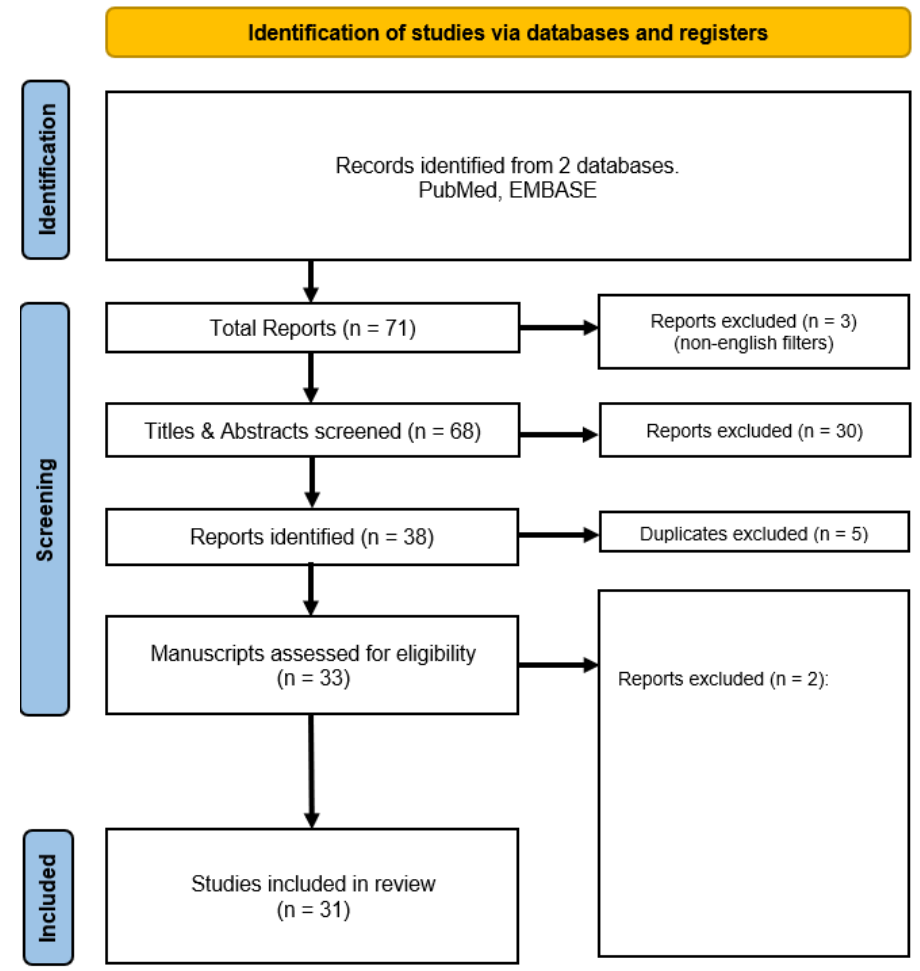

Figure 1. Flow chart of the study selection process. Exclusion criteria for reports included non-English language, books, theses, conference papers, comments, duplicates, and irrelevant content. 
Discussion on techniques, technology, and advances in SN identification and biopsy were extracted. Specific techniques were then grouped for the results section and the relevant papers were presented together. Of the 31 studies that were included in this review, 7 discussed multiple methods of detecting sentinel lymph nodes; 5 discussed lymphoscintigraphy/use of radioactive dye; 5 discussed use of computed tomography (CT) and/or single-photon emission computed tomography (SPECT); 5 studies discussed use of near-infrared fluorescence imaging; 4 studies discussed use of magnetic resonance imaging (MRI); and 5 studies discussed the use of on $\left[{ }^{18} \mathrm{~F}\right]$-fluorodeoxyglucose-positron emission tomography (FDG-PET).

\section{Results}

\subsection{Lymphoscintigraphy}

Lymphoscintigraphy is the detection of the gamma (y) radiation given off by radioactive tracers that are injected into the body. It is performed preoperatively to inform surgical lymph node dissection. The most commonly used radiotracer is ${ }^{99 \mathrm{~m}}$ Technetium, used to label a colloid, such as a sulphur compound or albumin. ${ }^{99 \mathrm{~m}} \mathrm{Tc}$ is used as it is less irradiating than some of the early tracers developed (such as ${ }^{198} \mathrm{Au}$ ) [40]. These were initially detected by planar gamma (y) cameras but this was shown to have a low detection rate of only $23 \%$ of patients by Liedberg et al. in their pilot study of 75 patients [18]. Reasons for this could include extensive metastasis obstructing the passage of lymph in the vessels (therefore, preventing the tracer reaching further downstream or forcing it to go to the contralateral side), and radioactive interference from the primary injection, site preventing nearby "hot spots" to be discerned (the "shine-through effect").

Despite the benefits of preoperative lymphatic visualisation and SLN localisation, there are difficulties with low detection rates. Additionally, the general limitations of radiotracer use (summarised below) prevent planar lymphoscintigraphy replacing current pre- or intraoperative modalities.

Blue dyes (for example, Patent Blue) can also be injected similarly to radiotracers. They add a visually distinct marker to lymph nodes, allowing for easier visual intraoperative detection. They are also cost effective, and application is relatively easy [18]. However, in the study by Liedberg et al., they found there was a low detection rate of $2.67 \%$ in their 75-patient cohort [18]. They also found that if it was not correctly applied into the bladder muscular wall, it could stain the entire operating area blue, obscuring resection margins.

Handheld y-probes are another method of detecting metastatic LNs intraoperatively using radiotracers injected similarly to the previous methods. They indicate the areas of highest radioactivity, likely where the radiotracer has accumulated in LNs. Hotspots are displayed on a 2D black background making correlation with the patient's anatomy challenging. It has been shown to have a higher detection rate than either preoperative lymphoscintigraphy or intraoperative blue dye detection. Indeed, this radio-guided surgery was reported by Liedberg et al. to identify additional SLNs in 7 patients after cystectomy and extended PLND had been performed, showing y-probes' utility to intraoperatively detect SLNs beyond the PLND template [18]. However, use of handheld y-probes is limited by lack of anatomical information and does not prevent the limitations of metastasis blocking lymph flow and the "shine-through effect". This makes intraoperative anatomical visualisation necessary [41].

Limitations of radiotracer use apply to all the three methods mentioned in this section. Limitations include radiation exposure to patients and staff, strong legislative control, limited radiotracer availability, expensive detectors and radiotracers, strong initial signals causing "shine through" (a particular concern in bladder cancer as the injection site in the bladder mucosa will be near many of the perivesical LNs of interest), long preparation times, limited half-life of ${ }^{99 \mathrm{~m}} \mathrm{Tc}(6 \mathrm{~h})$, allergies to blue dyes, viral transmission (through the albumin-based ${ }^{99 \mathrm{~m}}$ Tc colloids as this is derived from human blood), and dependency on nuclear medicine units [42]. 


\subsection{Computed Tomography (CT)/Single-Photon Emission Computer Tomography (SPECT)}

Lymphadenectomy and histology are widely regarded as the most accurate methods for detecting metastatic deposits in lymph nodes. However, their association with morbidity - and, rarely, mortality - resulted in CT being explored as one of the first alternatives to evaluating and staging bladder cancer [23]. CT and MRI are now routinely utilised to stage advanced disease in candidates for radical cystectomy [43].

The initial use of CT showed low sensitivity and a high false-negative rate as it relied on visibly enlarged lymph nodes to detect disease spread. Of note, there are benign causes of enlarged lymph nodes, and the internal architecture of the nodes could not be discerned. The node itself may also be lost between the "slices" depending on its size [23,31]. Paik et al. reported CT resulted in accurate staging of $54.9 \%$ of LNs, with $39 \%$ under-staging and $6.1 \%$ over-staging [25].

Single-photon emission computer tomography (SPECT) is an imaging modality that uses radiotracers similarly to other methods mentioned above, but images the radiation given off with a gantry of y-cameras, using software to then create a 3D map of radiation hot spots. Studies combining CT with SPECT have the anatomical benefits of CT with the functional benefits of lymphoscintigraphy imaging [44].

The benefits of this technique were demonstrated by Polom et al., who compared these methods in a study of 38 patients with N0 staging according to CT/MRI [22]. The method involved injecting ${ }^{99 \mathrm{~m}} \mathrm{Tc}$-nanocolloid peritumourly via cystoscopy, then Hybrid SPECT/CT was performed 3-8 h later. This technetium tracer is a nanoparticle of radioactive ${ }^{99 \mathrm{~m}} \mathrm{Tc}$, releasing y radiation. Preoperative SPECT/CT has repeatedly been shown to significantly impact surgical approach. Polom et al. found using SPECT/CT altered surgical approach in $7.8 \%$ of cases to include resection of lymph nodes outside the PLND template. This method is also effective in melanoma, prostate, cervical, and endometrial cancers [45-48]. For example, Veenstra et al. using SPECT/CT found additional SLNs in 20\% of cases and additional anatomical information in $31 \%$ of cases than current methods. This then altered the surgical approach in $29 \%$ of cases due to new information [45]. A particular benefit of preoperative SPECT/CT may be in obese patients where intraoperative SLN identification is more challenging, with Lerman et al. reporting an increase in intraoperative identification from $56 \%$ to $87 \%$ when SPECT/CT was used in these patients [24].

The limitations of SPECT are that it does not solve the issue of false-negative lymph nodes due to metastasis obstruction [24]. It is also a time-consuming and expensive process, requiring earlier admission to allow the SPECT/CT to be performed and interpreted preoperatively, relying on nuclear medicine staff, and has the limitations of radiotracer use, as mentioned earlier.

\subsection{Positron Emission Tomography (PET)}

Positron Emission Tomography (PET) scans use radioactive tracers to create 3D images similar to SPECT, but where SPECT uses tracers that release gamma rays, PET uses tracers that produce positrons which interact with local electrons in the body, releasing energy through photons, which are then detected [44]. The tracer used for this modality is ${ }^{18} \mathrm{~F}$ fluorodeoxyglucose (FDG), meaning the scan is often referred to as FDG-PET. This glucose analogue differentiates PET from other imaging modalities, as the FDG acts as a proxy for the metabolism of glucose in the body, meaning PET allows functional imaging rather than structural imaging. Its utility in oncology is widely recognised due to the increased metabolic demand of neoplastic cells causing increased FDG uptake to these areas [49]. This also means that PET can potentially identify metastases in normal sized lymph nodes as it is not reliant on structural changes, unlike conventional CT/MRI. The main use of FDG-PET may be in evaluating lymph nodes deemed suspicious by CT/MRI. This is shown by Dason et al., who studied routine preoperative use of FDG-PET in 185 patients, and found a sensitivity of $92 \%$ and a specificity of $91 \%$ among 51 suspicious LNs [35]. This combined use of PET and CT/MRI can effectively rule out suspicious LNs. However, they also found low sensitivities (7-23\%) in patients found to be N0 on CT. This is likely 
due to the low burden of disease with smaller median metastasis diameters, meaning less metabolic requirement and FDG uptake. As such, Dason et al. recommended that FDG-PET should not be used routinely in candidates for radical cystectomy, particularly if they lack clinically suspicious lymph nodes [35].

FDG-PET was initially explored to address the weaknesses of CT in detection of sentinel lymph nodes. Large studies by Schöder and Powles have been unable to replicate the encouraging results from smaller studies such as Kosuda et al. and Drieskens et al. [6,40,41,50]. It also has a higher radiation dosage than $\mathrm{CT}$, is less widely available, more expensive, has a longer acquisition time, and has a higher rate of incidental findings, which prompt further invasive testing, cost, and anxiety for patients [35]. FDG is also excreted in the urine which interferes with bladder and perivesical LN assessment. Methods to address this include pre-hydration to dilute urinary tracer, bladder catheterisation to limit tracer accumulation, forced diuresis, and using alternative tracers, such as ${ }^{11} \mathrm{C}$-choline, ${ }^{11} \mathrm{C}$-acetate, and ${ }^{11} \mathrm{C}$ methionine, which demonstrate less urinary excretion. Use of alternative tracers has been shown to be comparable to conventional staging methods [37,43]. However, among 25 patients, Nayak et al. showed a sensitivity of $96 \%$ of detecting primary tumours with FDG-PET after forced diuresis with IV Furosemide (20-40 mg) compared with $92 \%$ using CT, and a sensitivity of $78 \%$ when detecting positive LNs compared with $44 \%$ with CT, suggesting that FDG currently remains the best choice [39].

\subsection{Magnetic Resonance Imaging (MRI)}

MRI works by using powerful magnets to detect energy released from proton spin displacement to discern between types of tissue [51]. MRI is another imaging modality which requires changes in lymph node size or aberrant contrast enhancement to detect disease spread. As a result, it generally shows similar results to CT, as both modalities rely on lymph node morphology [31]. Although both CT and MRI are routinely used to stage disease in candidates for radical cystectomy, MRI has been shown to have a higher summary sensitivity-60\% (CT-40\%) [43]. Methods to address its weaknesses include using diffusion-weighted MRI (DW-MRI) and the use of ultra-small, superparamagnetic particles of iron oxide (USPIO) nanoparticles.

DW-MRI studies the random thermal motion of water molecules in the form of an apparent diffusion coefficient (ADC). The random diffusion of water is generally more restricted in neoplastic tissues than normal tissue due to the higher cell density and the abundance of intra- and extracellular membranes. Therefore, neoplastic tissues have lower ADCs than that of regular tissue. Papalia et al. showed the ADC of metastatic lymph nodes was significantly lower than that of regular lymph nodes [31]. The ADC represents an advantage over CT, and conventional MRI as it is not associated with lesion size. However, DW-MRI does have its own limits. ADC depends on many variables, such as body temperature, tissue pressure, perfusion rate, and magnetic environment, and the interpretation is operator-dependent [31]. Many of these could be addressed by using an in situ comparison from elsewhere in the body, but this requires further study. The results of DW-MRI showed: a sensitivity of $76.4 \%$; a specificity of $89.4 \%$; a positive predictive value (PPV) of 86.6\%; and a negative predictive value (NPV) of 71.4\% [31]. Despite Papalia et al. discerning a significant difference between metastatic and non-metastatic lymph nodes, the limitations of small sample size and the further study needed to develop an organ-based ADC reference still stand.

Ultra-small superparamagnetic particles of iron oxide (USPIO) can be used with preand post-administration MRIs, as well as continuously using handheld magnetometers to guide SLN dissection (similar to how y-probes are used). USPIO are nanoparticles that are injected intravenously which are then carried by the lymph vessels to the nodes. In the nodes, macrophages take them up where the iron oxide's properties cause a hypointense signal (appears darker). In lymph nodes containing malignant cells, the absence of macrophages results in a relatively hyperintense signal from the lack of iron oxide uptake-which is used in SLN identification [32]. Examples of USPIO include Ferumoxtran- 
10 (SineremÒ, Guerbet, France) and Sienna+ (Endomagnetics LTD, Cambridge, UK). Sienna+ is being used in breast cancer to localise SLNs with the SentiMag ${ }^{\circledR}$ detection system (Endomagnetics LTD, Cambridge, UK) [42]. Thill et al. found this modality to be equivalent to the current gold standard in breast cancer of using ${ }^{99 \mathrm{~m}} \mathrm{Tc}$ radiotracer for detecting SLNs when compared in parallel, intraoperatively, with the same patient population [42]. An added benefit of Sienna+ is that it can be visually identified intraoperatively due to its dark brown colour [42]. To avoid interference with the magnetometer, polymer instruments must be used intraoperatively, preparation time is $20 \mathrm{~min}$ compared with up to $29 \mathrm{~h}$ required for radiotracers, and the tracer can be injected intraoperatively if using a handheld detection system [42]. This may be applicable to bladder cancer as well.

Many groups studying USPIO-enhanced MRI did not compare their results to that of extended PLND (the gold standard), limiting the accuracy of their negative predictive values. Triantafyllou et al. did compare their results with extended PLND and studied detection of metastases in normal sized lymph nodes (addressing the limitation of spatial resolution in conventional MRI) [33]. They reported a sensitivity of $55.0 \%$, a specificity of $85.5 \%$, a PPV of $57.9 \%$, and an NPV of $83.9 \%$ in normal sized lymph nodes (where micro-metastases are more likely to be found). However, studying normal sized lymph nodes may have contributed to the relatively low diagnostic accuracy (77.3\%) reported, and having false-negative lymph nodes in $41.5 \%$ of patients prevents USPIO-enhanced MRI replacing extended PLND [33]. Deserno et al. similarly showed that USPIO use increased sensitivity from $76 \%$ to $96 \%$ and NPV from $91 \%$ to $98 \%$ between pre- and post-contrast MRIs [52].

Birkhäuser et al. combined DW-MRI and use of USPIO in a trial of 75 patients with N0 bladder cancer according to CT/MRI [34]. They demonstrated an improvement to staging for this patient group, with $65-75 \%$ of histopathologically proven LN metastases being detected by the 3 readers, with sensitivities from $65 \%$ to $75 \%$, specificities from $93 \%$ to $96 \%$, and a $25-35 \%$ false-negative rate, suggesting improvement over sole DW-MRI use [34]. Comparison of USPIO-DW-MRI with the pre- and post-USPIO enhancement MRI method described by Deserno et al. showed a similar degree of accuracy; however, the USPIODW-MRI method required significantly less time to interpret than comparison of the preand post-contrast images that the Deserno method required (13 min vs. $80 \mathrm{~min}$ per patient, respectively) [32]. Additionally, it may be assumed that the USPIO-DW-MRI images were relatively easy to interpret, as the radiologists who reviewed them were not familiar with the technique.

MRI avoids many of the drawbacks of radiotracer use mentioned above. It also has the benefit of providing results faster than histopathological analysis (interpretation in minutes rather than hours). However, MRI has a high initial cost, slow acquisition, and requires expertise to interpret the results. In addition, USPIO-enhanced MRI, requiring a pre- and post-contrast scan, would further delay progress, as $24-36 \mathrm{~h}$ must be kept between the 2 scans.

\subsection{Indocyanine Green (ICG) Near Infrared (NIR) Fluorescence}

Optical imaging using near-infrared (NIR) fluorescence has emerged recently as a safe, real-time method of identifying lymph nodes intraoperatively. It uses intravenous injection of a fluorescent dye indocyanine green (ICG), which has a peak absorption in the NIR wavelength range $(820 \mathrm{~nm})$. This means it can be detected by these NIR waves at depths of $5-10 \mathrm{~mm}$ in tissues [27]. As the NIR spectrum is also outside visible light, it does not affect the surgical field. ICG's half-life within the body is around 3-4 min and is excreted by the liver [27].

This technique has already enjoyed some success in identifying SLNs, with Jewell et al. identifying $95 \%$ of SLNs in their trial of 227 patients with uterine and cervical cancers by injecting ICG intracervically [53], and Schaafsma et al. achieving a $92 \%$ detection rate in patients with high grade bladder cancer when appropriately distending the bladder to maximise lymph drainage [28]. 
Polom et al. compared NIR ICG fluorescence with ${ }^{99 \mathrm{~m}} \mathrm{Tc}$ radiotracer use in detecting SLNs in 47 patients with MIBC [13]. They reported NIR ICG imaging detected all the same lymph nodes as ${ }^{99 \mathrm{~m}} \mathrm{Tc}$, but also managed to detect further LNs that the radiotracer did not in $25.6 \%$ of patients, leading to statistically significant differences in outcomes.

NIR ICG fluorescence imaging has the potential to improve bilateral SLN mapping without the drawbacks of a radiotracer, like those of ${ }^{99 \mathrm{~m}} \mathrm{Tc}$, and allows observation of live lymphatic outflow. Its visualisation properties were shown to be more helpful intraoperatively than blue dye by Brouwer et al., who visualised $96.8 \%$ of SLNs with ICG in their trial of 65 patients with penile cancer, compared with $55.7 \%$ of SLNs using blue dye [41]. Additionally, fluorescence imaging of the dissected SLNs that were not visualised intraoperatively in this study confirmed the presence of fluorescence, suggesting they were obscured by other tissue intraoperatively. They were also studying the utility of combining the optical properties of ICG with the radioactive properties of ${ }^{99 \mathrm{~m}} \mathrm{Tc}$ using the combined formulation to use gamma radiation and visual detection to guide sentinel lymph node dissection. This means the current standard of SLN mapping using radiotracer is preserved, with the added benefit of visual fluorescence lasting up to (and possibly beyond) $27 \mathrm{~h}$ after tracer injection without additional injection, allowing for a broader range of surgical protocols [41]. ICG may be considered superior to blue dye for the intended purpose of intraoperative visualisation of SLNs.

ICG NIR fluorescence-guided lymph node dissection has limitations as well. It seems to be more effective in patients with lower BMIs, with Jewell et al. finding a significant difference in median BMI of those with successful mapping $\left(30 \mathrm{~kg} / \mathrm{m}^{2}\right)$ and those with unsuccessful mapping $\left(41.2 \mathrm{~kg} / \mathrm{m}^{2}\right)$, most likely due to the limited tissue penetration NIR offers [53]. This tissue penetrance is another limitation of ICG NIR fluorescence as it is inferior to that of radioactive signals [41]. Advances in fluorescence imaging may expand the utility of ICG NIR fluorescence in the future.

\section{Discussion}

Detection of sentinel lymph nodes in urinary bladder cancer is an ongoing challenge. Current detection methods using CT and MRI have well documented benefits and limitations. Such anatomical imaging modalities rely on detecting abnormal sizes of lymph nodes. This means that metastases in normal sized lymph nodes are often missed, leading to a proportion of patients being under-staged and contributing to the relatively high false-negative rate $(25-40 \%)$ of these modalities $[6,34,50,54,55]$. The false-negative rate is the single most important index of diagnostic performance in sentinel lymph node detection, as positive nodes that are not detected and therefore not dissected may seed further metastases.

Anatomical imaging modalities, such as CT and MRI, rely on discernible, concerning changes that can be seen in lymph nodes, leading to lower sensitivity (particularly in early disease where changes may not be visually obvious). However, their ubiquitous nature and relatively low cost compared with more specialist methods means they remain useful as early steps in the diagnostic pathway.

Functional imaging is possible using FDG-PET and DW-MRI. These modalities are not restricted to detecting visually discernible changes and therefore can be used to detect earlier stages of disease. They are also useful in detecting disease spread where conventional staging has left uncertainty, such as assessing suspicious LNs found on CT/MRI.

Another exciting technique which can augment the results from existing imaging modalities is the use of radiomics studies, which involve extracting quantitative data from medical images and using machine learning to analyse these to answer a clinical question $[56,57]$. This field has already shown success in differentiating tumour grade in bladder cancer using radiomics features extracted from MRI images [58]. This work has been further expanded to develop and validate MRI- and CT-based radiomics signatures for preoperative prediction of lymph node metastases, demonstrating a favourable discrimination ability in both $[59,60]$. A similar discrimination ability was also demonstrated in 
the MRI-reported LN-negative population, which is encouraging, as CT and MRI tend to under-stage patients and may miss LN metastases, as mentioned previously.

Current evidence shows that use of radioactive tracers for lymphoscintigraphy provide most utility when combined with use of handheld y-probes intraoperatively. This is further enhanced when an imaging modality is used to add anatomical detail which is missing from this combination. This could be in the form of preoperative SPECT or combined SPECT-CT, which has been shown to significantly affect management plans in PLND in bladder cancer compared with conventional staging.

Methods that introduce radioactive (for example ${ }^{99 \mathrm{~m}} \mathrm{Tc}$, blue dye), magnetic (for example USPIO), and fluoroscopic (for example ICG) tracers all have the advantage of being able to identify SLNs outside the standard PNLD template, improving dissection yield and modifying the surgical approach to account for these. They can also help address the phenomenon of "skip lesions", where metastatic LNs are found above the common iliac bifurcation (outside the pelvic region) [61]. This phenomenon may occur due to upstream lymph nodes being obstructed by tumour cells or limitations in the studies, meaning upstream lymph nodes were not detected. Imaging modalities, such as lymphoscintigraphy, SPECT, USPIO-enhanced MRI, and fluoroscopy (where a tracer may flow irrespective of arbitrary anatomical boundaries), would all be beneficial in SLN identification in this scenario.

High false-negative results in many studies may be due to the bilateral nature of bladder lymphatic drainage independent of tumour side ("crossover phenomenon"). This was observed by various studies, and varied between $7 \%$ and $45 \%$ [4,14,15]. This may lead to concurrent sentinel lymph node appearances along different drainage pathways.

Systematic reviews and meta-analyses in oesophageal, cervical, and breast cancers show that lower-grade tumours are associated with higher detection rates of SLNs, suggesting that SLN biopsy should be limited to lower T stages (T1 and T2) [62-65], which was also reflected in Zarifmahmoudi et al.'s single-centre experience of 41 bladder cancer patients, with a detection rate of 75\% in T3-T4 patients and 94\% in T1-T2 patients [20]. However, LN staging in early disease progression cannot be clearly recommended, because, unfortunately, most studies included patients with advanced bladder cancer, meaning further evidence on detection of LN status in earlier disease is limited. Furthermore, many studies did not correlate the clinical lymph node status of the patient with the results from the detection modalities.

Assessment of prognostic factors is essential to guide treatment decisions and patient counselling. Cancer staging is most commonly used as a predictive tool for overall outcomes of bladder cancer, which can feed into the more specific prognostic markers for lymph node dissection, such as lymph node status and number of dissected LNs. An increasing number of dissected LNs demonstrated continued improvement in probability of survival. However, the therapeutic utility of lymph node dissection in bladder cancer and the association of extent of dissection with prognosis have limited and inconsistent evidence [66]. This is further complicated by lymph node density and number of dissected nodes, which are used to define adequate PLND. As Bruins et al. show in their systematic review, performing lymph node dissection confers favourable outcomes compared with no lymph node dissection for patients undergoing radical cystectomy in MIBC, and should be routinely performed for this cohort [67]. Despite weak evidence based on retrospective, non-randomised studies with high risks of bias and confounding, there appears to be some consensus on the extended PLND (e-PLND) showing better recurrence-free survival (RFS) and disease-specific survival (DSS) than lesser degrees of dissection [67-70]. However, the anatomical boundaries of e-PLND (which some argue is up to the level of the inferior mesenteric artery) are not consistent across studies [71]. Additionally, the first prospective, multicentre phase 3 trial studying lymph node templates failed to show improved outcomes with RFS, DSS or overall survival with e-PLND compared with lesser degrees of dissection [72]. Shariat et al. studied the probability of survival of bladder cancer patients and determined lymph node dissection limited to the true pelvis may be adequate for Ta and Tis stages to provide $>90 \%$ probability of survival; whereas, an e-PLND may be 
required for the same effect in patients with $\mathrm{T} 1$ or higher cancer [65]. However, it is hoped that an ongoing prospective trial with a larger sample size will be able to clarify the role of e-PLND further and establish clear recommendations regarding PLND extent [73].

Neoadjuvant chemotherapy has been shown to improve overall survival in patients with bladder cancer through phase 3 multicentre trials and meta-analyses [74,75]. However, due to the variable response rate many patients will not benefit from this. This, combined with the difficulty in identifying the cohort who would benefit, means it is not used as often as guidelines may recommend [76]. Therefore, identifying patients who are at high risk of LN metastases through functional and augmented imaging using radiomics or tracers helps identify the patients where e-PLND and neoadjuvant chemotherapy might be appropriate.

The limitations of all the SLN detection studies include the lack of node-to-node correlation between imaging modality and gold standard histopathologic analysis, and differences in study design - the experience of the reporting radiologist, enhancement technique, tracer choice and size, criteria defining positive lymph nodes, administration of neoadjuvant chemotherapy, staging of patient cohorts, non-standardised PLND templates, imaging equipment, and extent of lymphadenectomy [43]. This means that individual discrepancies in detection outcome between modalities cannot be compared, and patients are often used as units of analysis (leading to heterogenous and often incomparable results). This is exemplified by the sensitivity range from $33 \%$ to $100 \%$ and specificity range from $58 \%$ to $100 \%$, found by Crozier et al. in their systematic review and meta-analysis comparing imaging modalities in bladder cancer staging prior to radical cystectomy [43].

A common limitation across most of the studies we included is the issue of being underpowered and mostly monocentric. Additionally, 5 studies that were included in this paper were non-systematic reviews, and 20 out of 31 studies included were heterogenous prospective studies. The variety of methodologies, variability in quality of research, risk of bias, and confounding factors limit the conclusions that can be drawn from them.

There is currently no consensus on routine use of FDG-PET, USPIO-enhanced MRI, or fluoroscopy for nodal staging. While each of these methods have had positive findings with regard to higher sensitivity than CT alone, they are unlikely to replace it currently, due to the speed of results and wide availability CT offers.

Further study is needed to characterise the utility of these anatomical, radioactive, and functional detection modalities (individually and in combination), through independent testing; this is necessary because the current evidence base-largely consisting of non-randomised, heterogenous studies-cannot support changes to surgical or chemotherapeutic strategies. Despite promising initial results from newer modalities using USPIOenhanced MRI, DW-MRI, SPECT/CT, and ICG NIR fluoroscopy, the current evidence basis limits any clear recommendations to change guidelines for detection of sentinel lymph nodes in bladder cancer. Large, multicentre, prospective trials are needed to confidently support such a change; however, the use of these novel modalities secondary to current methods to determine the status of suspicious lymph nodes has shown success and demonstrated clinical utility.

Recent advancements in technology have seen a rapid development in lymph node mapping methodologies. More work is needed to validate these modalities, but they represent an enticing prospect of more sensitive and anatomically accurate sentinel lymph nodes detection, allowing earlier detection and prevention of disease progression, and-by helping to guide the extent and limits of lymph node dissection during radical cystectomyimproving the quality of this lifesaving procedure.

Author Contributions: Conceptualization, N.V., J.T. and K.D.; methodology, A.S., A.W. and J.H.; formal analysis, A.S.; data curation, A.S., A.W. and J.H.; writing-original draft preparation, A.S.; writing-review and editing, A.S., A.W., J.H. and N.V.; supervision, N.V. All authors have read and agreed to the published version of the manuscript.

Funding: This research received no external funding.

Conflicts of Interest: The authors declare no conflict of interest. 


\section{References}

1. Tomlinson, B.; Lin, T.Y.; Dall'Era, M.; Pan, C.X. Nanotechnology in bladder cancer: Current state of development and clinical practice. Nanomedicine 2015, 10, 1189. [CrossRef] [PubMed]

2. Avis, N.E.; Smith, K.W.; McGraw, S.; Smith, R.G.; Petronis, V.M.; Carver, C.S. Assessing quality of life in adult cancer survivors (QLACS). Qual. Life Res. 2005, 14, 1007-1023. [CrossRef] [PubMed]

3. Avis, N.E.; Deimling, G.T. Cancer survivorship and aging. Cancer 2008, 113, 3519-3529. [CrossRef] [PubMed]

4. Sherif, A.; Garske, U.; de La Torre, M.; Thörn, M. Hybrid SPECT-CT: An Additional Technique for Sentinel Node Detection of Patients with Invasive Bladder Cancer. Eur. Urol. 2006, 50, 83-91. [CrossRef]

5. Bassi, P.; Ferrante, G.D.; Piazza, N.; Spinadin, R.; Carando, R.; Pappagallo, G.; Pagano, F. Prognostic factors of outcome after radical cystectomy for bladder cancer: A retrospective study of a homogeneous patient cohort. J. Urol. 1999, 161, $1494-1497$. [CrossRef]

6. Aljabery, F.; Shabo, I.; Olsson, H.; Gimm, O.; Jahnson, S. Radio-guided sentinel lymph node detection and lymph node mapping in invasive urinary bladder cancer: A prospective clinical study. BJU Int. 2017, 120, 329-336. [CrossRef]

7. Dorin, R.P.; Daneshmand, S.; Eisenberg, M.S.; Chandrasoma, S.; Cai, J.; Miranda, G.; Nichols, P.W.; Skinner, D.G.; Skinner, E.C. Lymph node dissection technique is more important than lymph node count in identifying nodal metastases in radical cystectomy patients: A comparative mapping study. Eur. Urol. 2011, 60, 946-952. [CrossRef]

8. Liss, M.A.; Noguchi, J.; Lee, H.J.; Vera, D.R.; Kader, A.K. Sentinel lymph node biopsy in bladder cancer: Systematic review and technology update. Indian J. Urol. 2015, 31, 170-175. [CrossRef]

9. Cabanas, R. An approach for the treatment of penile carcinoma. Cancer 1977, 39, 456-466. [CrossRef]

10. Tanis, P.J.; Nieweg, O.E.; Valdés Olmos, R.A.; Rutgers, E.J.T.; Kroon, B.B.R. History of sentinel node and validation of the technique. Breast Cancer Res. 2001, 3, 109-112. [CrossRef]

11. Wong, G.; Greenhalgh, T.; Westhorp, G.; Buckingham, J.; Pawson, R. RAMESES publication standards: Meta-narrative reviews. J. Adv. Nurs. 2013, 69, 987-1004. [CrossRef] [PubMed]

12. Zarifmahmoudi, L.; Ghorbani, H.; Sadri, K.; Tavakkoli, M.; Keshvari, M.; Salehi, M.; Sadeghi, R. Sentinel Node Biopsy in Urothelial Carcinoma of the Bladder: Systematic Review and Meta-Analysis. Urol. Int. 2019, 103, 373-382. [CrossRef] [PubMed]

13. Polom, W.; Markuszewski, M.; Cytawa, W.; Czapiewski, P.; Lass, P.; Matuszewski, M. Fluorescent Versus Radioguided Lymph Node Mapping in Bladder Cancer. Clin. Genitourin. Cancer 2017, 15, e405-e409. [CrossRef]

14. Lusuardi, L.; Janetschek, G. Update on use of enhanced imaging to optimize lymphadenectomy in patients undergoing minimally invasive surgery for urothelial cancer of the bladder. Curr. Urol. Rep. 2013, 14, 124-129. [CrossRef] [PubMed]

15. Salminen, A.P.; Jambor, I.; SyvÄnen, K.T.; BostrÖm, P.J. Update on Novel Imaging Techniques for the detection of lymph node metastases in bladder cancer. Minerva Urol. Nefrol. 2016, 68, 138-149.

16. Nissenkorn, I.; Winkler, H.; Servadio, C.; Melloul, M.; Lubin, E.; Idelsohn, A.R.; Hadar, H. A comparative evaluation of lymphoscintigraphy versus lymphangiography and computerized tomography scanning in diagnosis of lymph node metastases in advanced bladder cancer. J. Urol. 1986, 136, 825-827. [CrossRef]

17. Aljabery, F.; Lindblom, G.; Skoog, S.; Shabo, I.; Olsson, H.; Rosell, J.; Jahnson, S. PET/CT versus conventional CT for detection of lymph node metastases in patients with locally advanced bladder cancer. BMC Urol. 2015, 15, 87. [CrossRef]

18. Liedberg, F.; Chebil, G.; Davidsson, T.; Gudjonsson, S.; Månsson, W. Intraoperative sentinel node detection improves nodal staging in invasive bladder cancer. J. Urol. 2006, 175, 84-88. [CrossRef]

19. Marits, P.; Karlsson, M.; Sherif, A.; Garske, U.; Thörn, M.; Winqvist, O. Detection of immune responses against urinary bladder cancer in sentinel lymph nodes. Eur. Urol. 2006, 49, 59-70. [CrossRef]

20. Zarifmahmoudi, L.; Ghorbani, H.; Sadeghi, R.; Sadri, K.; Tavakkoli, M.; Keshvari, M.; Salehi, M. Sentinel lymph node biopsy in muscle-invasive bladder cancer: Single-center experience. Ann. Nucl. Med. 2020, 34, 718-724. [CrossRef]

21. Sherif, A.; De La Torre, M.; Malmström, P.U.; Thörn, M. Lymphatic mapping and detection of sentinel nodes in patients with bladder cancer. J. Urol. 2001, 166, 812-815. [CrossRef]

22. Połom, W.; Markuszewski, M.; Cytawa, W.; Lass, P.; Matuszewski, M. Radio-guided lymph node mapping in bladder cancer using SPECT/CT and intraoperative $\gamma$-probe methods. Clin. Nucl. Med. 2016, 41, e362-e367. [CrossRef] [PubMed]

23. Salo, J.O.; Kivisaari, L.; Rannikko, S.; Lehtonen, T. The value of CT in detecting pelvic lymph node metastases in cases of bladder and prostate carcinoma. Scand. J. Urol. Nephrol. 1986, 20, 261-265. [CrossRef]

24. Lerman, H.; Metser, U.; Lievshitz, G.; Sperber, F.; Shneebaum, S.; Even-Sapir, E. Lymphoscintigraphic sentinel node identification in patients with breast cancer: The role of SPECT-CT. Eur. J. Nucl. Med. Mol. Imaging 2006, 33, 329-337. [CrossRef] [PubMed]

25. Paik, M.L.; Scolieri, M.J.; Brown, S.L.; Spirnak, J.P.; Resnick, M.I. Limitations of computerized tomography in staging invasive bladder cancer before radical cystectomy. J. Urol. 2000, 163, 1693-1696. [CrossRef]

26. Patel, M.N.; Hemal, A.K. Molecular Targeted Fluorescence-Guided Intraoperative Imaging of Bladder Cancer Nodal Drainage Using Indocyanine Green During Radical and Partial Cystectomy. Curr. Urol. Rep. 2016, 17, 74. [CrossRef]

27. Aoun, F.; Albisinni, S.; Zanaty, M.; Hassan, T.; Janetschek, G.; Velthoven, R. van Indocyanine greenfluorescence-guidedsentinel lymph node identification in urologic cancers: A systematic review and meta-analysis. Minerva Urol. Nefrol. 2018, 70, 361-369. [CrossRef] 
28. Schaafsma, B.E.; Verbeek, F.P.R.; Elzevier, H.W.; Tummers, Q.R.J.G.; Van Der Vorst, J.R.; Frangioni, J.V.; Van De Velde, C.J.H.; Pelger, R.C.M.; Vahrmeijer, A.L. Optimization of Sentinel Lymph Node Mapping in Bladder Cancer using Near-Infrared Fluorescence Imaging. J. Surg. Oncol. 2014, 110, 845. [CrossRef]

29. Manny, T.B.; Hemal, A.K. Fluorescence-enhanced robotic radical cystectomy using unconjugated indocyanine green for pelvic lymphangiography, tumor marking, and mesenteric angiography: The initial clinical experience. Urology 2014, 83, 824-830. [CrossRef]

30. Knapp, D.W.; Adams, L.G.; DeGrand, A.M.; Niles, J.D.; Ramos-Vara, J.A.; Weil, A.B.; O’Donnell, M.A.; Lucroy, M.D.; Frangioni, J.V. Sentinel Lymph Node Mapping of Invasive Urinary Bladder Cancer in Animal Models Using Invisible Light. Eur. Urol. 2007, 52, 1700-1709. [CrossRef]

31. Papalia, R.; Simone, G.; Grasso, R.; Augelli, R.; Faiella, E.; Guaglianone, S.; Cazzato, R.; Del Vescovo, R.; Ferriero, M.; Zobel, B.; et al. Diffusion-weighted magnetic resonance imaging in patients selected for radical cystectomy: Detection rate of pelvic lymph node metastases. BJU Int. 2012, 109, 1031-1036. [CrossRef]

32. Thoeny, H.C.; Triantafyllou, M.; Birkhaeuser, F.D.; Froehlich, J.M.; Tshering, D.W.; Binser, T.; Fleischmann, A.; Vermathen, P.; Studer, U.E. Combined ultrasmall superparamagnetic particles of iron oxide-enhanced and diffusion-weighted magnetic resonance imaging reliably detect pelvic lymph node metastases in normal-sized nodes of bladder and prostate cancer patients. Eur. Urol. 2009, 55, 761-769. [CrossRef] [PubMed]

33. Triantafyllou, M.; Studer, U.E.; Birkhäuser, F.D.; Fleischmann, A.; Bains, L.J.; Petralia, G.; Christe, A.; Froehlich, J.M.; Thoeny, H.C. Ultrasmall superparamagnetic particles of iron oxide allow for the detection of metastases in normal sized pelvic lymph nodes of patients with bladder and/or prostate cancer. Eur. J. Cancer 2013, 49, 616-624. [CrossRef] [PubMed]

34. Birkhäuser, F.D.; Studer, U.E.; Froehlich, J.M.; Triantafyllou, M.; Bains, L.J.; Petralia, G.; Vermathen, P.; Fleischmann, A.; Thoeny, H.C. Combined ultrasmall superparamagnetic particles of iron oxide-enhanced and diffusion-weighted magnetic resonance imaging facilitates detection of metastases in normal-sized pelvic lymph nodes of patients with bladder and prostate cancer. Eur. Urol. 2013, 64, 953-960. [CrossRef]

35. Dason, S.; Wong, N.C.; Donahue, T.F.; Meier, A.; Zheng, J.; Mannelli, L.; Di Paolo, P.L.; Dean, L.W.; McPherson, V.A.; Rosenberg, J.E.; et al. Utility of routine preoperative 18F-fluorodeoxyglucose positron emission tomography-computed tomography (18F-FDG PET/CT) in identifying pathologic lymph node metastases at radical cystectomy. J. Urol. 2020, 204, 254. [CrossRef]

36. Abrahamsson, J.; Aaltonen, K.; Engilbertsson, H.; Liedberg, F.; Patschan, O.; Rydén, L.; Sjödahl, G.; Gudjonsson, S. Circulating tumor cells in patients with advanced urothelial carcinoma of the bladder: Association with tumor stage, lymph node metastases, FDG-PET findings, and survival. Urol. Oncol. Semin. Orig. Investig. 2017, 35, 606.e9-606.e16. [CrossRef] [PubMed]

37. Powles, T.; Murray, I.; Brock, C.; Oliver, T.; Avril, N. Molecular positron emission tomography and PET/CT imaging in urological malignancies. Eur. Urol. 2007, 51, 1511-1521. [CrossRef]

38. Schöder, H.; Larson, S.M. Positron emission tomography for prostate, bladder, and renal cancer. Semin. Nucl. Med. 2004, 34, 274-292. [CrossRef]

39. Nayak, B.; Dogra, P.N.; Naswa, N.; Kumar, R. Diuretic 18F-FDG PET/CT imaging for detection and locoregional staging of urinary bladder cancer: Prospective evaluation of a novel technique. Eur. J. Nucl. Med. Mol. Imaging 2013, 40, 386-393. [CrossRef]

40. International Atomic Energy Agency. Radiopharmaceuticals for Sentinel Lymph Node Detection: Status and Trends; International Atomic Energy Agency: Vienna, Austria, 2015.

41. Brouwer, O.R.; Van Den Berg, N.S.; Mathéron, H.M.; Van Der Poel, H.G.; Van Rhijn, B.W.; Bex, A.; Van Tinteren, H.; Valdés Olmos, R.A.; Van Leeuwen, W.B.; Horenblas, S. A Hybrid Radioactive and Fluorescent Tracer for Sentinel Node Biopsy in Penile Carcinoma as a Potential Replacement for Blue Dye. Eur. Urol. 2014, 65, 600-609. [CrossRef]

42. Thill, M.; Kurylcio, A.; Welter, R.; van Haasteren, V.; Grosse, B.; Berclaz, G.; Polkowski, W.; Hauser, N. The Central-European SentiMag study: Sentinel lymph node biopsy with superparamagnetic iron oxide (SPIO) vs. radioisotope. Breast 2014, 23, 175-179. [CrossRef] [PubMed]

43. Crozier, J.; Papa, N.; Perera, M.; Ngo, B.; Bolton, D.; Sengupta, S.; Lawrentschuk, N. Comparative sensitivity and specificity of imaging modalities in staging bladder cancer prior to radical cystectomy: A systematic review and meta-analysis. World J. Urol. 2019, 37, 667-690. [CrossRef] [PubMed]

44. Nuclear Medicine. Available online: https://www.nibib.nih.gov/science-education/science-topics/nuclear-medicine (accessed on 8 December 2021).

45. Veenstra, H.J.; Klop, W.M.C.; Speijers, M.J.; Lohuis, P.J.F.M.; Nieweg, O.E.; Hoekstra, H.J.; Balm, A.J.M. Lymphatic drainage patterns from melanomas on the shoulder or upper trunk to cervical lymph nodes and implications for the extent of neck dissection. Ann. Surg. Oncol. 2012, 19, 3906-3912. [CrossRef]

46. Vermeeren, L.; Valdés Olmos, R.A.; Meinhardt, W.; Bex, A.; Van Der Poel, H.G.; Vogel, W.V.; Sivro, F.; Hoefnagel, C.A.; Horenblas, S. Value of SPECT/CT for detection and anatomic localization of sentinel lymph nodes before laparoscopic sentinel node lymphadenectomy in prostate carcinoma. J. Nucl. Med. 2009, 50, 865-870. [CrossRef] [PubMed]

47. Sawicki, S.; Kobierski, J.; Łapińska-Szumczyk, S.; Lass, P.; Cytawa, W.; Bianek-Bodzak, A.; Wydra, D. Comparison of SPECT-CT results and intraoperative detection of sentinel lymph nodes in endometrial cancer. Nucl. Med. Commun. 2013, 34, 590-596. [CrossRef] [PubMed]

48. Wydra, D.; Sawicki, S.; Wojtylak, S.; Bandurski, T.; Emerich, J. Sentinel node identification in cervical cancer patients undergoing transperitoneal radical hysterectomy: A study of 100 cases. Int. J. Gynecol. Cancer 2006, 16, 649-654. [CrossRef] 
49. Ashraf, M.A.; Goyal, A. Fludeoxyglucose (18F); StatPearls: Treasure Island, FL, USA, 2021.

50. Daneshmand, S.; Ahmadi, H.; Huynh, L.N.; Dobos, N. Preoperative staging of invasive bladder cancer with dynamic gadoliniumenhanced magnetic resonance imaging: Results from a prospective study. Urology 2012, 80, 1313-1318. [CrossRef]

51. Magnetic Resonance Imaging (MRI). Available online: https:/ / www.nibib.nih.gov/science-education/science-topics/magneticresonance-imaging-mri (accessed on 8 December 2021).

52. Deserno, W.M.L.L.G.; Harisinghani, M.G.; Taupitz, M.; Jager, G.J.; Witjes, J.A.; Mulders, P.F.; Hulsbergen Van De Kaa, C.A.; Kaufmann, D.; Barentsz, J.O. Urinary bladder cancer: Preoperative nodal staging with ferumoxtran-10-enhanced MR imaging. Radiology 2004, 233, 449-456. [CrossRef]

53. Jewell, E.L.; Huang, J.J.; Abu-Rustum, N.R.; Gardner, G.J.; Brown, C.L.; Sonoda, Y.; Barakat, R.R.; Levine, D.A.; Leitao, M.M. Detection of sentinel lymph nodes in minimally invasive surgery using indocyanine green and near-infrared fluorescence imaging for uterine and cervical malignancies. Gynecol. Oncol. 2014, 133, 274-277. [CrossRef]

54. Lodde, M.; Lacombe, L.; Friede, J.; Morin, F.; Saourine, A.; Fradet, Y. Evaluation of fluorodeoxyglucose positron-emission tomography with computed tomography for staging of urothelial carcinoma. BJU Int. 2010, 106, 658-663. [CrossRef]

55. Goodfellow, H.; Viney, Z.; Hughes, P.; Rankin, S.; Rottenberg, G.; Hughes, S.; Evison, F.; Dasgupta, P.; O’Brien, T.; Khan, M.S. Role of fluorodeoxyglucose positron emission tomography (FDG PET)-computed tomography (CT) in the staging of bladder cancer. BJU Int. 2014, 114, 389-395. [CrossRef]

56. Lambin, P.; Leijenaar, R.T.H.; Deist, T.M.; Peerlings, J.; De Jong, E.E.C.; Van Timmeren, J.; Sanduleanu, S.; Larue, R.T.H.M.; Even, A.J.G.; Jochems, A.; et al. Radiomics: The bridge between medical imaging and personalized medicine. Nat. Rev. Clin. Oncol. 2017, 14, 749-762. [CrossRef] [PubMed]

57. Gillies, R.J.; Kinahan, P.E.; Hricak, H. Radiomics: Images Are More than Pictures, They Are Data. Radiology 2016, 278 , 563-577. [CrossRef] [PubMed]

58. Zhang, X.; Xu, X.; Tian, Q.; Li, B.; Wu, Y.; Yang, Z.; Liang, Z.; Liu, Y.; Cui, G.; Lu, H. Radiomics assessment of bladder cancer grade using texture features from diffusion-weighted imaging. J. Magn. Reson. Imaging 2017, 46, 1281-1288. [CrossRef] [PubMed]

59. Wu, S.; Zheng, J.; Li, Y.; Wu, Z.; Shi, S.; Huang, M.; Yu, H.; Dong, W.; Huang, J.; Lin, T. Development and Validation of an MRI-Based Radiomics Signature for the Preoperative Prediction of Lymph Node Metastasis in Bladder Cancer. EBioMedicine 2018, 34, 76-84. [CrossRef] [PubMed]

60. Wu, S.; Zheng, J.; Li, Y.; Yu, H.; Shi, S.; Xie, W.; Liu, H.; Su, Y.; Huang, J.; Lin, T. A Radiomics Nomogram for the Preoperative Prediction of Lymph Node Metastasis in Bladder Cancer. Clin. Cancer Res. 2017, 23, 6904-6911. [CrossRef] [PubMed]

61. Tarin, T.V.; Power, N.E.; Ehdaie, B.; Sfakianos, J.P.; Silberstein, J.L.; Savage, C.J.; Sjoberg, D.; Dalbagni, G.; Bochner, B.H. Lymph node-positive bladder cancer treated with radical cystectomy and lymphadenectomy: Effect of the level of node positivity. Eur. Urol. 2012, 61, 1025-1030. [CrossRef]

62. Sadeghi, R.; Shafiei, S.; Bagheri, R.; Sadri, K.; Hossein Jafarian, A.; Attaran, D.; Mohammadzadeh Lari, S.; Basiri, R.; Mohammad Hashem Asnaashari, A.; Lari, M.S.; et al. Sentinel node mapping for intra-thoracic malignancies: Systematic review of the best available evidence. Rev. Clin. Med. 2015, 2, 52-57.

63. Kadkhodayan, S.; Hasanzadeh, M.; Treglia, G.; Azad, A.; Yousefi, Z.; Zarifmahmoudi, L.; Sadeghi, R. Sentinel node biopsy for lymph nodal staging of uterine cervix cancer: A systematic review and meta-analysis of the pertinent literature. Eur. J. Surg. Oncol. 2015, 41, 1-20. [CrossRef]

64. Abdollahi, A.; Jangjoo, A.; Dabbagh Kakhki, V.R.; Rasoul Zakavi, S.; Memar, B.; Naser Forghani, M.; Mehrabibahar, M.; Sadeghi, R. Factors affecting sentinel lymph node detection failure in breast cancer patients using intradermal injection of the tracer. Rev. Esp. Med. Nucl. 2010, 29, 73-77. [CrossRef]

65. Shariat, S.F.; Ehdaie, B.; Rink, M.; Cha, E.K.; Svatek, R.S.; Chromecki, T.F.; Fajkovic, H.; Novara, G.; David, S.G.; Daneshmand, S.; et al. Platinum Priority-Bladder Cancer Clinical Nodal Staging Scores for Bladder Cancer: A Proposal for Preoperative Risk Assessment; Alexandre, R.Z., Ed.; Eleviser: Amsterdam, The Netherlands, 2012; Volume 61, pp. 237-242.

66. Wang, Y.C.; Wu, J.; Dai, B.; Shen, Y.J.; Ma, C.G.; Ye, D.W.; Zhu, Y.P. Extended versus non-extended lymphadenectomy during radical cystectomy for patients with bladder cancer: A meta-analysis of the effect on long-term and short-term outcomes. World J. Surg. Oncol. 2019, 17, 1-9. [CrossRef] [PubMed]

67. Bruins, H.M.; Veskimae, E.; Hernandez, V.; Imamura, M.; Neuberger, M.M.; Dahm, P.; Stewart, F.; Lam, T.B.; N’Dow, J.; Van Der Heijden, A.G.; et al. The impact of the extent of lymphadenectomy on oncologic outcomes in patients undergoing radical cystectomy for bladder cancer: A systematic review. Eur. Urol. 2014, 66, 1065-1077. [CrossRef] [PubMed]

68. Bi, L.; Huang, H.; Fan, X.; Li, K.; Xu, K.; Jiang, C.; Liu, H.; Dong, W.; Zhang, S.; Yang, X.; et al. Extended vs non-extended pelvic lymph node dissection and their influence on recurrence-free survival in patients undergoing radical cystectomy for bladder cancer: A systematic review and meta-analysis of comparative studies. BJU Int. 2014, 113, E39-E48. [CrossRef]

69. Mandel, P.; Tilki, D.; Eslick, G.D. Extent of lymph node dissection and recurrence-free survival after radical cystectomy: A meta-analysis. Urol. Oncol. Semin. Orig. Investig. 2014, 32, 1184-1190. [CrossRef] [PubMed]

70. Małkiewicz, B.; Kiełb, P.; Gurwin, A.; Knecht, K.; Wilk, K.; Dobruch, J.; Zdrojowy, R. The Usefulness of Lymphadenectomy in Bladder Cancer-Current Status. Medicina 2021, 57, 415. [CrossRef] [PubMed]

71. Kitamura, H.; Masumori, N.; Tsukamoto, T. Role of lymph node dissection in management of bladder cancer. Int. J. Clin. Oncol. 2011, 16, 179-185. [CrossRef] [PubMed] 
72. Gschwend, J.E.; Heck, M.M.; Lehmann, J.; Rübben, H.; Albers, P.; Wolff, J.M.; Frohneberg, D.; de Geeter, P.; Heidenreich, A.; Kälble, T.; et al. Extended Versus Limited Lymph Node Dissection in Bladder Cancer Patients Undergoing Radical Cystectomy: Survival Results from a Prospective, Randomized Trial. Eur. Urol. 2019, 75, 604-611. [CrossRef]

73. S1011 Standard or Extended Pelvic Lymphadenectomy in Treating Patients Undergoing Surgery for Invasive Bladder Cance. ClinicalTrials.gov. Available online: https:/ / clinicaltrials.gov/ct2/show/NCT01224665 (accessed on 14 February 2022).

74. International Collaboration of Trialists, on behalf of the Medical Research Council Advanced Bladder Cancer Working Party (now the National Cancer Research Institute Bladder Cancer Clinical Studies Group) the European Organisation for Research and Treatment of Cancer Genito-Urinary Tract Cancer Group; the Australian Bladder Cancer Study Group; the National Cancer Institute of Canada Clinical Trials Group; Finnbladder, Norwegian Bladder Cancer Study Group; Club Urologico Espanol de Tratamiento Oncologico Group. International phase III trial assessing neoadjuvant cisplatin, methotrexate, and vinblastine chemotherapy for muscle-invasive bladder cancer: Long-term results of the BA06 30894 trial. J. Clin. Oncol. 2011, 29, 2171-2177. [CrossRef]

75. Vale, C.L. Neoadjuvant chemotherapy in invasive bladder cancer: Update of a systematic review and meta-analysis of individual patient data advanced bladder cancer (ABC) meta-analysis collaboration. Eur. Urol. 2005, 48, 202-206. [CrossRef]

76. Witjes, J.A.; Lebret, T.; Compérat, E.M.; Cowan, N.C.; De Santis, M.; Bruins, H.M.; Hernández, V.; Linares Espinós, E.; Dunn, J.; Rouanne, M.; et al. Updated 2016 EAU Guidelines on Muscle-invasive and Metastatic Bladder Cancer. Eur. Urol. 2017, 71, 462-475. [CrossRef] 